\title{
Assessment of effective borehole thermal resistance from operational data
}

\author{
Olga Mikhaylova
}

\author{
Ian W. Johnston
}

\author{
Guillermo A. Narsilio
}

\begin{abstract}
Ground source beat pump (GSHP) systems use the ground as a source of sustainable thermal energy for heating and cooling of buildings. Efficient design of the ground heat exchangers (GHEs) for these systems is important so that long-term operation is adequate, efficient and cost-effective. Several design methods have been developed to size GHEs, and many of these methods, including the widely used ASHRAE method, use an effective borehole thermal resistance to model thermal processes in boreholes. A correct estimation of this parameter is crucial for an adequate sizing of borehole GHEs. This study estimates an experimental effective borehole thermal resistance of the borehole GHEs of an operating GSHP system based on monitoring data collected during the Elizabeth Blackburn School of Sciences full-scale shallow geothermal operational study in Melbourne, Australia. The experimental resistance is compared with the resistances predicted using several analytical and numerical methods. It was found that the experimental resistance can be significantly different from the resistances predicted by these other methods. The paper discusses possible reasons for such differences.
\end{abstract}

\section{INTRODUCTION}

For adequate design of ground heat exchangers (GHEs), their thermal performance has to be predicted for the expected thermal loads applied to the ground over the lifetime of a ground source heat pump (GSHP) system. Classic analytical models, such as infinite line source, finite line source or infinite cylindrical source models, estimate GHE wall temperatures at a particular time of GHE operation (Li and Lai, 2015). To calculate temperatures of the fluid circulating in the GHEs, thermal fluxes from the GHE walls to the fluid have to be estimated or assigned. In most borehole models, heat transfer inside GHEs is assumed to be steady-flux and thermal capacity of GHEs is not taken into consideration (see an extensive literature review on this topic in Shirazi and Bernier (2013)). Considering this, thermal processes inside borehole GHEs are often described by steady-state borehole thermal resistances. The borehole thermal resistances that consider thermal short-circuiting between tubes of GHEs are referred to as the effective borehole thermal resistances, $R_{b}^{*}$ (Hellström 1991; Beier and Spitler 2016; Spitler, et al. 2016).

For relatively short boreholes of depths less than about $100 \mathrm{~m}$, short-circuiting does not affect the GHE resistance much (Spitler, et al. 2016). In such cases, $R_{b}^{*}$ can be estimated as a parameter that relates the mean fluid temperature of the GHE, $T_{m}$, to its mean borehole wall temperature, $T_{b}$, through a constant unit heat transfer rate applied to the borehole and averaged along its depth, $q_{b}$ (for example, Lamarche, et al. (2010)) as shown in Equation 1.

Olga Mikhaylova (omikhaylova@unimelb.edu.au) is a PhD Candidate, Ian W. Johnston is a Professorial Fellow and Guillermo A. Narsilio is a Senior Lecturer at The University of Melbourne. 


$$
T_{m}=T_{b}+R_{b}^{*} q_{b}
$$

In practice, $R_{b}^{*}$ can be evaluated by conducting an in-situ thermal response test (TRT) on a pilot GHE (Spitler and Gehlin, 2015). If a TRT is not performed on site, the design $\mathrm{R}^{*} b$ can be estimated analytically or numerically using anticipated GHE geometry and grout and ground thermal properties. When models are used, thermal properties of the ground and grout as well as geometry of GHEs have to be well predicted for an accurate estimation of $R^{*} b$ values. In addition, analytical and numerical solutions are built on certain assumptions, so the accuracy of $R_{b}^{*}$ estimated by these methods can be affected by these assumptions.

This study estimates experimental effective borehole thermal resistance $R_{b e}^{*}$ of an operational GSHP system. The monitoring data collected for the full-scale GSHP system of the Elizabeth Blackburn School of Sciences in Melbourne, Australia was used for the estimations. The $R_{b e}^{*}$ value determined is compared with the values of borehole thermal resistances $R_{b}$ calculated analytically and numerically. The comparison shows that the values of $R_{b}$ estimated by models can be significantly different from the value of $R_{b e}^{*}$ estimated experimentally. Probable reasons of these differences are discussed herein.

\section{EXPERIMENTAL EFFECTIVE BOREHOLE THERMAL RESISTANCE}

A $120 \mathrm{~kW}$ (34.1 tons) GSHP system was installed in the 1,500 $\mathrm{m}^{2}\left(16,146 \mathrm{ft}^{2}\right)$ two-storey Elizabeth Blackburn School of Sciences (EBSS) in Melbourne, Australia to provide heating and cooling energy for the building. The system has twenty-eight 50m (164ft) deep double U-loop borehole GHEs installed under and around the building footprint. Based on the continuous core samples collected from the site, the site is underlain by effectively intact and imperious Silurian mudstone from around $1.5 \mathrm{~m}$ below the ground surface. The system was instrumented to monitor its performance and ground thermal responses to the GHEs. The system commenced operation in March 2014. More details about the set-up of this operational study and instrumentation can be found in Mikhaylova, et al. (2015). The operational performance of the system has been recorded continuously at 3-minute time intervals since the beginning of its operation. More than 2 years of this data has been collected.

In this study, a line of seven GHEs connected in parallel was selected for the analysis. A general view and a plan view cross-section of the GHEs of this line are shown in Figure 1. The GHEs of the line were installed at least $5 \mathrm{~m}$ $(16.4 \mathrm{ft})$ apart from each other and the GHEs of neighbouring lines. The ground temperatures observed suggest that there was no significant thermal interference between the GHEs of the selected line during the first 2 years of the system operation. In the estimations of $R_{b e}^{*}$ of the GHEs selected, the first 2 years of the monitoring data was considered and the individual GHEs in the line were treated as stand-alone GHEs.

The values of ground and grout thermal properties were measured in a laboratory. In the calculations, the ground and grout thermal conductivity and diffusivity were taken as average values along the depths of the GHEs. Table 1 summarises the thermal properties of the ground and grout and the "as designed" geometry of the GHEs. It should be noted that the actual geometry of the GHEs could be different from the "as designed" geometry due to installation processes. While extensive local experience with the Silutian mudstone suggests that changes in the borehole diameter are unlikely, as will be addressed later, the positions of the U-loops inside the boreholes can change significantly. 
a)

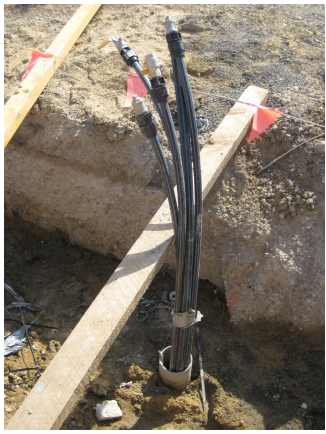

b)

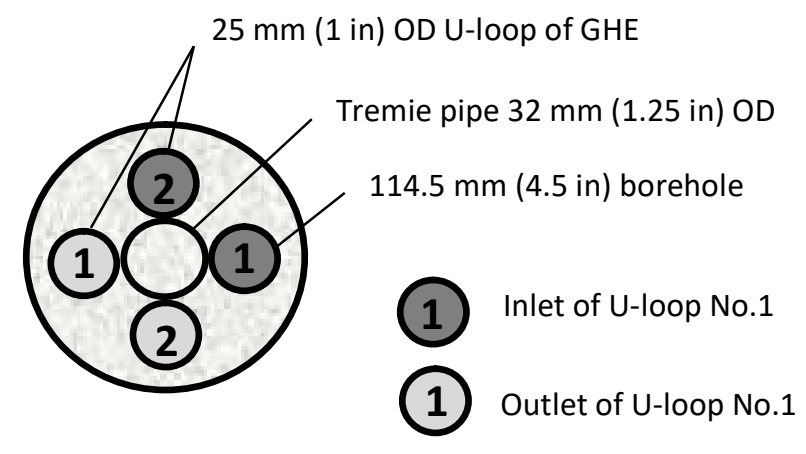

Figure 1 GHEs: a) A GHE being installed; b) A plan view cross-section of a GHE.

Table 1. Properties and geometry of the ground and GHEs

\begin{tabular}{|c|c|c|}
\hline Parameter & Units & Value \\
\hline \multirow{2}{*}{ Ground thermal conductivity, $k$} & $\mathrm{~W} /(\mathrm{m} \cdot \mathrm{K})$ & 2.7 \\
\hline & $\mathrm{Btu} / \mathrm{h} \cdot \mathrm{ft} \cdot{ }^{\circ} \mathrm{F}$ & 1.56 \\
\hline \multirow{2}{*}{ Ground thermal diffusivity, $\alpha$} & $\mathrm{m}^{2} /$ day & 0.123 \\
\hline & $\mathrm{ft}^{2} /$ day & 1.32 \\
\hline \multirow{2}{*}{ Grout thermal conductivity, $k_{\text {grout }}$} & $\mathrm{W} /(\mathrm{m} \cdot \mathrm{K})$ & 2.1 \\
\hline & $\mathrm{Btu} / \mathrm{h} \cdot \mathrm{ft} \cdot{ }^{\circ} \mathrm{F}$ & 1.21 \\
\hline \multirow{2}{*}{ Grout thermal diffusivity, $\alpha_{\text {grout }}$} & $\mathrm{m}^{2} /$ day & 0.073 \\
\hline & $\mathrm{ft}^{2} /$ day & 0.79 \\
\hline \multirow{2}{*}{ U-loop thermal conductivity, $k_{p i p e}$} & $\mathrm{~W} /(\mathrm{m} \cdot \mathrm{K})$ & 0.4 \\
\hline & $\mathrm{Btu} / \mathrm{h} \cdot \mathrm{ft} \cdot{ }^{\circ} \mathrm{F}$ & 0.23 \\
\hline \multirow{2}{*}{ Radius of borehole, $r_{\text {bore }}$} & $\mathrm{m}$ & 0.0570 \\
\hline & $\mathrm{ft}$ & 0.1870 \\
\hline \multirow{2}{*}{ External radius of U-loop pipes, $r_{p, e x t}$} & $\mathrm{~m}$ & 0.0125 \\
\hline & $\mathrm{ft}$ & 0.0410 \\
\hline \multirow{2}{*}{ Internal radius of U-loop pipes, $r_{p, i n}$} & $\mathrm{~m}$ & 0.0102 \\
\hline & $\mathrm{ft}$ & 0.0334 \\
\hline \multirow{2}{*}{ Centre-to-centre distance between U-loops, $L_{u}$} & $\mathrm{~m}$ & 0.0570 \\
\hline & $\mathrm{ft}$ & 0.1870 \\
\hline \multirow{2}{*}{ Internal convection coefficient, $h_{c o n v}$} & $\mathrm{~W} /\left(\mathrm{m}^{2} \cdot \mathrm{K}\right)$ & 1,000 \\
\hline & $\mathrm{Btu} / \mathrm{h} \cdot \mathrm{ft}^{2 \cdot}{ }^{\circ} \mathrm{F}$ & 176 \\
\hline
\end{tabular}

Since the GHEs of relatively short depths of $50 \mathrm{~m}$ are under investigation, Equation 1 is used to estimate effective borehole thermal resistances. To do so, the experimental effective borehole thermal resistance $R_{b e, i}^{*}$ at any particular time step $i$ was estimated from the general relationship between the unit power $q_{b, i}$ applied to the GHE at this time step and the difference between the mean fluid temperature $T_{m, i}$ and the mean borehole wall temperature $T_{b, i}$ at the same time step as

$$
R_{b e, i}^{*}=\frac{T_{m, i}-T_{b, i}}{q_{b, i}}
$$


The values of $\mathrm{R}^{*}{ }_{b, i}$ were calculated at 3-minute time steps for the times when the heat pumps were running. To do so, at each time step, the $T_{b, i}$ values were calculated considering a 4-month ground thermal load history aggregated into three constant power pulses and ground thermal resistances to these pulses. Considering this and Equation 2, $R_{b e, i}$ was calculated as

$$
R_{b e, i}^{*}=\frac{T_{m, i}-T_{g}-q_{5 h, i} R_{5 h}-q_{720 h, i} R_{720 h}-q_{2160, i} R_{2160 h}}{q_{5 h, i}}
$$

where $R_{5 b}, R_{720 b}$ and $R_{2160 b}$ are the ground thermal resistances to the $q_{5 b, i} q_{720 h, i}$ and $q_{2160 h, i}$ thermal pulses and $T_{g}$ is the initial undisturbed ground temperature measured on the site. This particular selection of the pulse durations is in line with some common GHE sizing guidelines (for example, ASHRAE (2011)) in regards to the selection of immediate and intermediate ground thermal pulse durations. It should be noted that this is one of many possible aggregations of ground thermal loads for such calculations. The infinite line source model (see, for example, Li and Lai (2015)) was used to calculate the resistances in Equation 3 using the ground and grout thermal properties measured in the laboratory (Table 1).

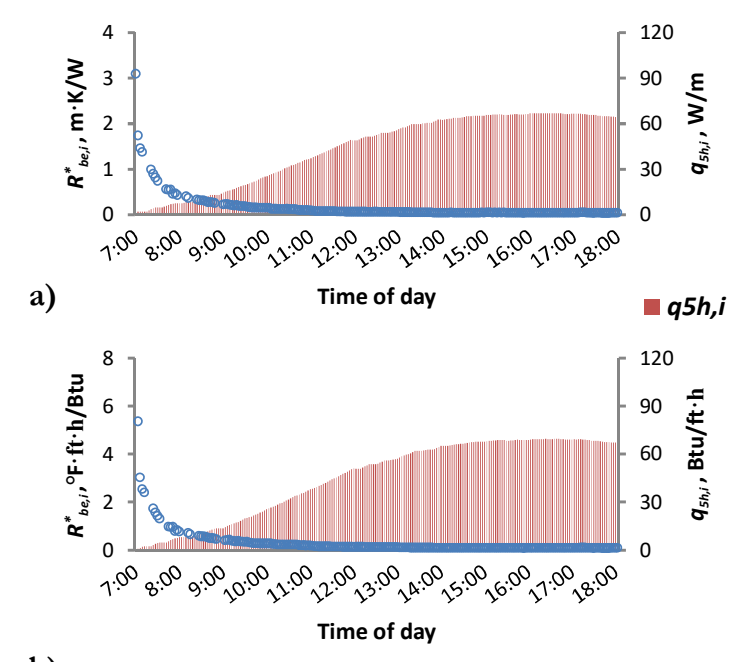

b)
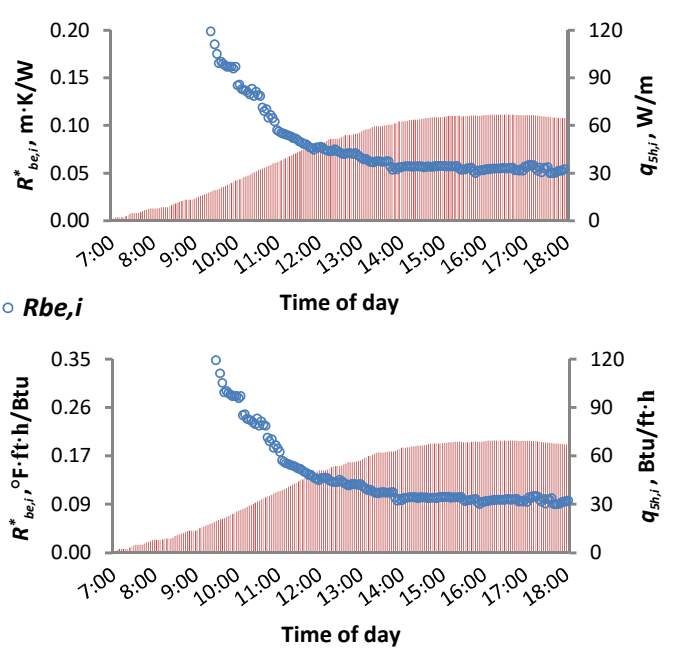

Figure 2 An estimation of $R_{b c i}^{*}$ and $q_{55, i}$ for 11 February 2015: a) the parameters are given in SI units and b) the parameters are given in US customary units.

For the $R_{b e}^{*}$ analyses, the days when the highest daily energy was applied to the GHEs were selected to minimise ground load averaging errors in estimations of $q_{5 b, i}$. During these days, the heat pumps tended to work continuously for long periods applying close to constant ground power to the GHEs. In total, eleven such days were selected. As an example, Figure 2 presents $q_{5 b, i}$ and $R_{b e, i}^{*}$ of the GHEs estimated for 11 February 2015. The $R_{b e, i}^{*}$ values estimated for all eleven days selected were plotted together in Figure 3. In Figures 2 and 3, $R_{b e, i}^{*}$ is presented at two scales to show changes in this parameter over time more clearly. 

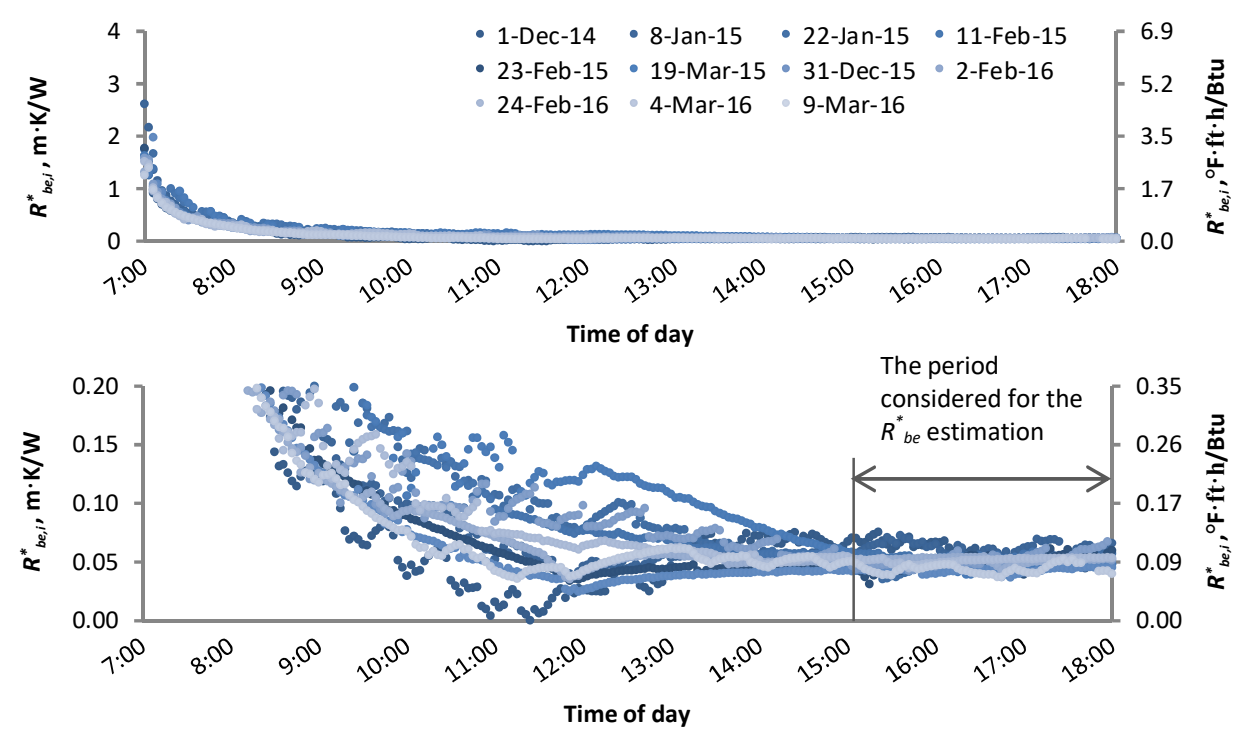

Figure $3 \quad R_{b e, i}^{*}$ of the eleven selected days.

From Figures 2 and 3, the initial high values of $R_{b e, i}^{*}$ estimated for the periods from 7:00 to around 15:00 indicate that the thermal absorption of the grout, the U-loop pipes and the water influenced the thermal fluxes inside the GHEs at the beginning of daily heat pump operations. However, it should be noted that the initial values of $R_{b e, i}^{*}$ estimated at each day can be affected by the load averaging errors. This is likely the case because, firstly, during the periods from 7:00 to 12:00 the $95 b, i$ values represent load history of the times before 7:00 when no power was applied to the GHEs. Secondly, during the first few hours of daily operation, the applied ground thermal power fluctuated significantly because of relatively moderate building cooling power demands at these times. Therefore, the values of the $R_{b e, i}^{*}$ presented here for the periods from 7:00 to around 15:00 should be considered with caution.

For the above reasons, the values of $R_{b e, i}^{*}$ estimated at periods from 15:00 to 18:00 only were used for the estimation of $R_{b e}^{*}$ of the GHEs. During these periods, when the values of $R_{b e, i}^{*}$ become nearly stable, the thermal processes inside the GHEs reach quasi steady-flux conditions. Such nearly stable values of $R_{b e, i}^{*}$ represent the resistance of the borehole GHEs to thermal power applied to the ground through them as defined by Equation 1 and are considered as effective borehole thermal resistances $R^{*}$ be determined experimentally. From Figure 3 , between the times of 15:00 to 18:00 of the eleven days selected, the $R_{b e, i}^{*}$ values of the GHEs fluctuated around the average value of $0.05 \mathrm{~m} \cdot \mathrm{K} / \mathrm{W}\left(0.085 \mathrm{~h} \cdot \mathrm{ft} \cdot{ }^{\circ} \mathrm{F} / \mathrm{Btu}\right)$ level. Hence, the representative value of the experimental effective borehole thermal resistance of the GHEs is estimated as $\mathrm{R}_{b e}^{*}=0.05 \mathrm{~m} \cdot \mathrm{K} / \mathrm{W}\left(0.085 \mathrm{~h} \cdot \mathrm{ft} \cdot{ }^{\circ} \mathrm{F} / \mathrm{Btu}\right)$. It should be noted that the estimated values of $R_{b e, i}^{*}$ plotted in Figure 3 can be affected by measurement errors similar to the measurement errors in TRT results (for an example of a TRT measurement error estimation see Witte (2013)). The measurement errors in $\mathrm{R}_{b e, i}^{*}$ values obtained in this study will be addressed in future publications.

\section{ANALYTICAL AND NUMERICAL BOREHOLE THERMAL RESISTANCES}

In this section, the borehole thermal resistances of the GHEs of the EBSS GSHP system were estimated using analytical and numerical models. In these estimations, $R_{b}$ was calculated as 


$$
R_{b}=R_{\text {grout }}+\frac{R_{p}+R_{\text {conv }}}{4}
$$

where $R_{g \text { rout }}$ is the grout resistance, $R_{p}$ is the conduction resistance for each tube of the U-loop and $R_{\text {ronv }}$ is the convection resistance inside each tube of the U-loop. $R_{p}=0.080 \mathrm{~m} \cdot \mathrm{K} / \mathrm{W}\left(0.136 \mathrm{~h} \cdot \mathrm{ft} \cdot{ }^{\circ} \mathrm{F} / \mathrm{Btu}\right)$ and $R_{\text {conv }}=$ $0.016 \mathrm{~m} \cdot \mathrm{K} / \mathrm{W}\left(0.027 \mathrm{~h} \cdot \mathrm{ft} \cdot{ }^{\circ} \mathrm{F} / \mathrm{Btu}\right)$ were estimated for the GHEs of the system (the calculations were made according to Philippe, et al. (2010)).

To calculate $R_{\text {grout }}$ of GHEs the following three methods were selected:

- The two-dimensional multipole equation for double U-loop borehole GHEs suggested by Conti, et al. (2016);

- The equivalent diameter method proposed by Shonder and Beck (2000);

- A two-dimensional numerical model of the GHE cross-section.

In the numerical model, the GHE was modelled using the same approach as was used by Loveridge and Powrie (2014) in their "pile only model" estimating thermal resistances of piles. In particular, a two-dimensional model of the GHE cross-section was considered in the finite element software TEMP/W. The model simulated only the grout; the plastic pipes of the U-loops and the tremie pipe as well as the GHE fluid were not considered in these simulations. As in Loveridge and Powrie (2014), the constant temperatures of $20^{\circ} \mathrm{C}\left(68^{\circ} \mathrm{F}\right)$ and $10^{\circ} \mathrm{C}\left(50{ }^{\circ} \mathrm{F}\right)$ were applied to the borehole wall and the U-loop pipe walls respectively. The heat flux between the borehole wall and the U-loop pipe walls was calculated to find the borehole thermal resistance of the grout at steady state conditions.

During the installation of the GHEs, it was observed that many spacers designed to keep the U-loops of the GHEs in place were lost which might affect the actual positions of the U-loops inside the GHEs. In addition, other factors might influence their positions such as grouting. Hence, the actual positions of the U-loops in the GHEs might not be the same as designed. It is not possible to establish the exact locations of the U-loops considering that there are many possible positions that the U-loops might take. To illustrate possible influences of the U-loop positions to $R_{b}$ of the GHEs, two extreme locations of the U-loops inside the boreholes were considered in addition to the "as designed" geometry of the borehole cross-section shown in Figure 4a. These locations are:

- "Pipes apart": the pipes of the U-loops are apart and touching the borehole sides, $L_{U}=0.086 \mathrm{~m}$ $(0.282 \mathrm{ft})$ (Figure 4b);

- "Pipes at centre": the pipes of the U-loops are at the centre of the GHE and touching, $L_{U}=0.035 \mathrm{~m}$ $(0.115 \mathrm{ft})$ (Figure 4c).

The positions of the individual pipes in both cases are symmetrical. Clearly, there are many other non-symmetrical locations of the pipes but these are not considered herein.

The values of $R_{b}$ estimated for the three U-loop locations by the three methods are plotted in Figure 5. From the figure, the values of $R_{b}$ for a particular U-loop location estimated by the multipole equation and the numerical method are very similar. For example, the multipole equation estimated $R_{b}$ for the "as designed" case as $0.066 \mathrm{~m} \cdot \mathrm{K} / \mathrm{W}$ $\left(0.112 \mathrm{~h} \cdot \mathrm{ft} \cdot{ }^{\circ} \mathrm{F} / \mathrm{Btu}\right)$, which is only marginally larger than the value of $0.062 \mathrm{~m} \cdot \mathrm{K} / \mathrm{W}\left(0.105 \mathrm{~h} \cdot \mathrm{ft}^{\circ} \cdot{ }^{\circ} \mathrm{F} / \mathrm{Btu}\right)$ estimated by the numerical method for the same case. Shonder and Beck's method calculated the highest value of $R_{b}$ for the "as designed" case among the values calculated by the all three methods which is equal to $0.086 \mathrm{~m} \cdot \mathrm{K} / \mathrm{W}$ $\left(0.146 \mathrm{~h} \cdot \mathrm{ft} \cdot{ }^{\circ} \mathrm{F} / \mathrm{Btu}\right)$. 

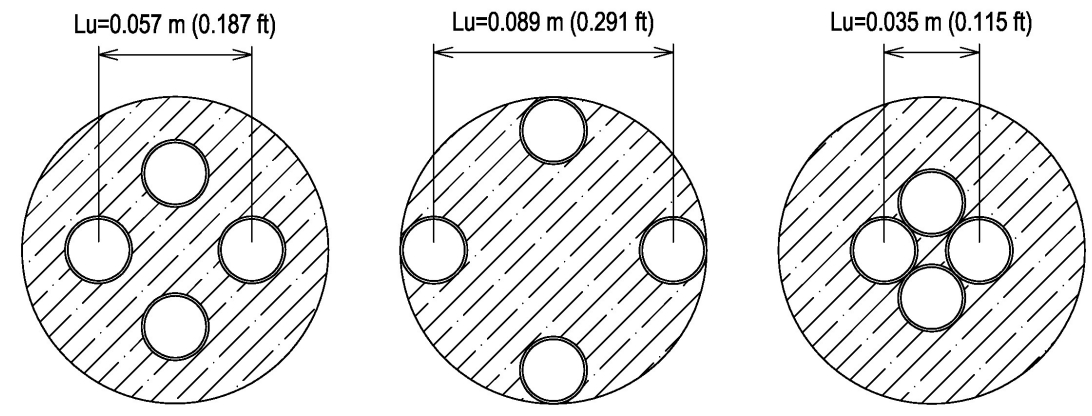

Figure 4 A plan view cross-section of GHEs: a) “as designed”, b) “pipes apart” and c) "pipes at centre” cases.

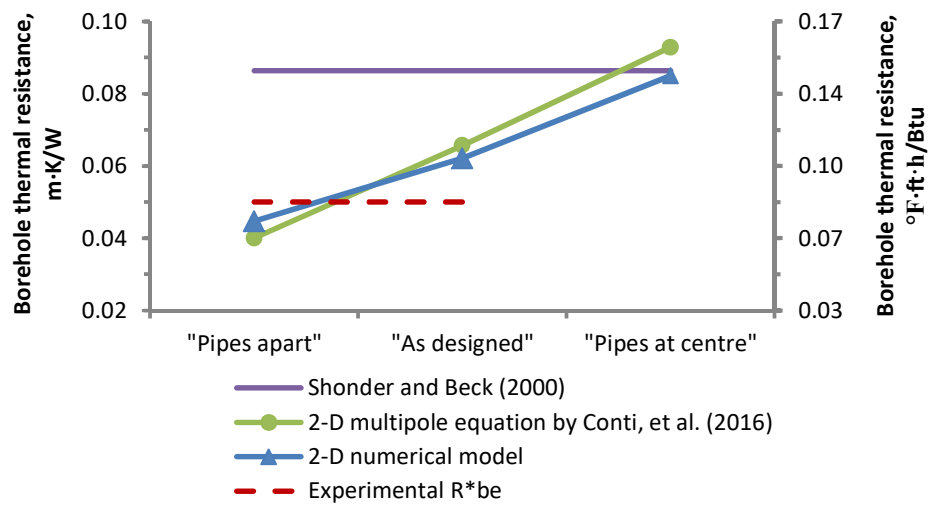

Figure 5 Comparison of $R_{b}$ estimated analytically and numerically and $R_{b e}^{*}$ estimated experimentally.

The estimations by the numerical model and multipole equation demonstrate the importance of the position of U-loop pipes for the value of $R_{b}$. For the particular case considered here, the value of $R_{b}$ can be in between $0.045 \mathrm{~m} \cdot \mathrm{K} / \mathrm{W}\left(0.077 \mathrm{~h} \cdot \mathrm{ft} \cdot{ }^{\circ} \mathrm{F} / \mathrm{Btu}\right)$ to $0.085 \mathrm{~m} \cdot \mathrm{K} / \mathrm{W}\left(0.145 \mathrm{~h} \cdot \mathrm{ft} \cdot{ }^{\circ} \mathrm{F} / \mathrm{Btu}\right)$ depending on pipe positions as estimated by the numerical model (Figure 5). This range can be even higher if the grout of lower thermal conductivity than the grout considered here is used for the GHEs. Shonder and Beck's method does not consider the location of U-loops inside GHEs, so the values of $R_{b}$ estimated by this method are the same for all three locations considered.

\section{COMPARISON OF OPERATIONAL AND MODELLED BOREHOLE THERMAL RESISTANCES}

In Figure 5, the value of $R_{b e}^{*}$ is plotted along with the values of $R_{b}$ estimated analytically and numerically. As observed, the value of $R^{*} b e=0.05 \mathrm{~m} \cdot \mathrm{K} / \mathrm{W}\left(0.085 \mathrm{~h} \cdot \mathrm{ft} \cdot{ }^{\circ} \mathrm{F} / \mathrm{Btu}\right)$ is lower than $R_{b}=0.062 \mathrm{~m} \cdot \mathrm{K} / \mathrm{W}\left(0.105 \mathrm{~h} \cdot \mathrm{ft} \cdot{ }^{\circ} \mathrm{F} / \mathrm{Btu}\right)$ and $0.066 \mathrm{~m} \cdot \mathrm{K} / \mathrm{W}\left(0.112 \mathrm{~h} \cdot \mathrm{ft} \cdot{ }^{\circ} \mathrm{F} / \mathrm{Btu}\right)$ estimated by the numerical model and the multipole equation respectively for the "as designed" position of the U-loops. At the same time, the $R^{*}$ be value is in between the values for the "as designed" and "pipes apart" cases calculated by both these methods. This might indicate that the actual location of the U-loops inside the GHEs is somewhere between these two positions. Such a location of the U-loops is likely. Indeed, the GHEs have a grouted tremie pipe in between the U-loops (see Figure 1b), so the U-loops cannot be closer together than the "as designed" case. At the same time, it is likely that a proportion of the U-loops may have moved 
from the centres towards edges of the boreholes during grouting.

From Figure 5 , the $R^{*}$ be value does not compare well with the $R_{b}$ values calculated by the equivalent diameter method proposed by Shonder and Beck (2000). The $R_{b}=0.086 \mathrm{~m} \cdot \mathrm{K} / \mathrm{W}\left(0.146 \mathrm{~h} \cdot \mathrm{ft} \cdot{ }^{\circ} \mathrm{F} / \mathrm{Btu}\right)$ calculated by this method is substantially different from the experimental $\mathrm{R}^{*}{ }_{b e}=0.05 \mathrm{~m} \cdot \mathrm{K} / \mathrm{W}\left(0.085 \mathrm{~h} \cdot \mathrm{ft} \cdot{ }^{\circ} \mathrm{F} / \mathrm{Btu}\right)$. Shonder and Beck's method assumes one-dimensional thermal processes inside GHEs and simplifies the two U-loops of a double U-loop GHE to a single pipe with the radius of $2 \cdot r_{p, e x t}$ at the centre of a borehole. This assumption seems to be close to the "pipes at centre" case of the U-loops location inside the GHEs. Considering this, it is logical that the value of $R_{b}$ calculated by Shonder and Beck's method is close to the values of $R_{b}$ calculated by the numerical model and the multipole equation for the "pipes at centre" location. This seems to be the case.

The comparison of $R_{b e}^{*}$ and $R_{b}$ indicates that the $R_{b}$ values estimated analytically and numerically for the "as designed" geometry of the GHEs are substantially different from the $R^{*}$ be values observed experimentally. The estimations suggest that a deviation of the actual U-loop positions inside the boreholes from their "as designed" positions can be one of the reasons of such differences. The second reason can be the specific assumptions of the models which might not be accurate for particular GHEs. The differences between actual values of borehole thermal resistances and the values of these parameters estimated during design can lead to oversizing or undersizing of GHEs (Mikhaylova, et al. 2016).

Overall, designers should be aware of the significant influence of the U-loop pipe position on the values of borehole thermal resistances. During installation of U-loops into boreholes, it is hard to ensure the correct spacing between the pipes of the U-loops. In some cases, spacers are used to separate the pipes, but some contractors prefer not to use them since they reduce flexibility of U-loops and make the installation process harder. Also, the spacers are frequently lost during installations. A possible measure to verify calculated values of $R_{b}$ is in-situ testing (TRTs) of GHEs. During a TRT, $R_{b}^{*}$ of an actual pilot GHE is measured. Since other GHEs of the same borefield would be installed following the same technological procedures, the TRT can provide additional information about likely effective borehole thermal resistances of the GHEs in the borefield to consider during their design. However, the values of the resistances obtained from TRTs can be affected by measuring errors. Also, it is not clear to what extend TRT results of a single GHE can represent all GHEs in a borefield. More comparisons, as the one performed here, may help to evaluate possible differences between calculated and measured resistances.

\section{CONCLUSION}

This study compares an experimentally determined effective borehole thermal resistance $R^{*}$ be of double U-loop GHEs with the resistances $R_{b}$ predicted analytically and numerically for the same GHEs. The monitoring data of a full-scale commercial GSHP system was used for this comparison. The analysis showed that the $R_{b}$ values estimated by models based on the design geometry of the GHEs can be significantly different from the $R_{b e}^{*}$ value determined experimentally. The $R_{b}$ value estimated by the equivalent diameter method differs from $R_{b e}^{*}$ the most. Possibly, the $U-$ loop design positions inside the boreholes changed during the installation of the GHEs because of installation processes which might have caused the differences between the predicted and observed resistances values.

The analysis showed the importance of the positions of U-loops inside borehole GHEs to the values of borehole thermal resistances. If these positions are changed during an installation, but $\mathrm{R}_{b}$ estimated analytically for the design geometry of GHEs, the GHE design lengths can be overestimated or underestimated. Designers should be aware of such possible errors in design lengths of GHEs. To improve estimations of $R_{b}$, in-situ thermal response tests can be performed on pilot GHEs to contribute to the estimation of $R_{b}$ values calculated by models.

\section{ACKNOWLEDGMENTS}

The authors would like to acknowledge the support provided by the Sustainable Energy Pilot Demonstration (SEPD) Program funded by the Department of Economic Development, Jobs, Transport and Resources of the State Government of Victoria, Australia. 


\section{REFERENCES}

ASHRAE (2011) Chapter 34: Geothermal Energy - ASHRAE Handbook: HV AC Applications. ASHRAE.

Beier, R.A. and J.D. Spitler. 2016. Weighted Average of Inlet and Outlet Temperatures in Borehole Heat Exchangers. Applied Energy 174: 118-129.

Conti, P., D. Testi and W. Grassi. 2016. Revised Heat Transfer Modeling of Double-U Vertical Ground-coupled Heat Exchangers. Applied Thermal Engineering 106: 1257-1267.

Hellström, G. 1991. Ground Heat Storage: Thermal Analyses of Duct Storage Systems, PhD Thesis, Lund University.

Lamarche, L., S. Kajl and B. Beauchamp. 2010. A Review of Methods to Evaluate Borehole Thermal Resistances in Geothermal Heat-pump systems. Geothermics 39(2): 187-200.

Li, M. and A.C.K. Lai. 2015. Review of Analytical Models for Heat Transfer by Vertical Ground Heat Exchangers (GHEs): A Perspective of Time and Space Scales. Applied Energy 151: 178-191.

Loveridge, F. and W. Powrie. 2014. 2D Thermal Resistance of Pile Heat Exchangers. Geothermics 50: 122-135.

Mikhaylova, O., I.W. Johnston, G.A. Narsilio, A.V. Kivi, R. Aditya and G. Noonan. 2015. Performance of Borehole Ground Heat Exchangers under Thermal Loads from a School Building: Full-scale Experiment in Melbourne, Australia. World Geothermal Congress 2015. Melbourne, Australia:19-25.

Mikhaylova, O., I.W. Johnston and G.A. Narsilio. 2016. Uncertainties in the Design of Ground Heat Exchangers. Environmental Geotechnics 3(4): 253-264.

Philippe, M., M. Bernier and D. Marchio. 2010. Sizing Calculation Spreadsheet Vertical Geothermal Borefields. ASHRAE Journal 52(7): 20-28.

Shirazi, A.S. and M. Bernier. 2013. Thermal Capacity Effects in Borehole Ground Heat Rxchangers. Energy and Buildings 67: $352-364$.

Shonder, J.A. and J.V. Beck. 2000. Field Test of a New Method for Determining Soil Formation Thermal Conductivity and Borehole Resistance. Oak Ridge National Lab., TN (US).

Spitler, J.D., S. Javed and R. Grundmann. 2016. Calculation Tool for Effective Borehole Thermal Resistance. 12th REHVA World Congress (Clima 2016), Aalborg, Denmark.

Spitler, J.D. and E.A. Gehlin. 2015. Thermal Response Testing for Ground Source Heat Pump Systems - An Historical Review. Renewable and Sustainable Energy Reviews 50: 1125-1137.

Witte, H.J.L. 2013. Error analysis of thermal response tests. Applied Energy 109: 302-311. 